\title{
$\checkmark$ A New Operation Hand Splint for Intrinsic Replacement Tendon Transfers
}

\author{
ERNEST P. FRITSCHI \\ Schieffelin Leprosy Research \& Training Centre, Karigiri, via Kat padi, \\ North Arcot District, Tamil Nadu 632 106, South India
}

For many years in several units which are practising tendon transfer surgery for the intrinsic minus hand in leprosy, a splint has been used to ensure the equalization of the tensions on the four slips of the transplanted tendons during suture (Fritschi, 1971).

This splint has been proved extremely useful, but it has had one major def ect namely, that the transverse metacarpal arch has not been maintained during the suturing of the tendons. This has tended to result in a lower tension on the medial fingers because the palm has been stretched out flat as it were. For this reason this splint has perhaps contributed to the tendency towards reversal of this very important arch.

Several workers have at various times stressed the importance of this arch (Antia, 1971; Boilean, Grant and Basmajian, 1965; Brand, 1958; Fritschi, 1971). Some operations have been devised to correct the arch (Beine, 1974; Ranney Donald, 1973), and have given some good results. The positioning splint has at one time been modified by tilting the axis of the metacarpophalangeal joints to the ulna side, but this does not seem to have made much difference, and it necessitated different splints for the left and right hands.

The accompanying illustration shows a new splint designed for the flexor approach which has been carved out of solid wood (Fig. 1) and which is now in use (Fig. 2). This splint has the same positions of wrist and M.P. joints as its antecedents, but provides a very definite curve in the metacarpal regions of the palm. Six grooves are provided for the fingers so that the same splint can be used for both hands by leaving two spare grooves empty between the index finger and the thumb. The thumb is also included in the splint and the opponens procedure is done in the same splint, by tilting it over on its side.

The splint is sterilized, just as its metal precursors were, by wrapping it in a cloth wrapper and autoclaving at $120^{\circ} \mathrm{C}$ for $20 \mathrm{~min}$, as is done for our wooden operating blocks and wooden skin stretchers for skin grafting. The use of wood for these purposes has been well and truly tried over many years, and has not been found wanting.

This splint has been in use for the past 6 months in this institution and we have found it very helpful indeed. It should also be said however, that the 

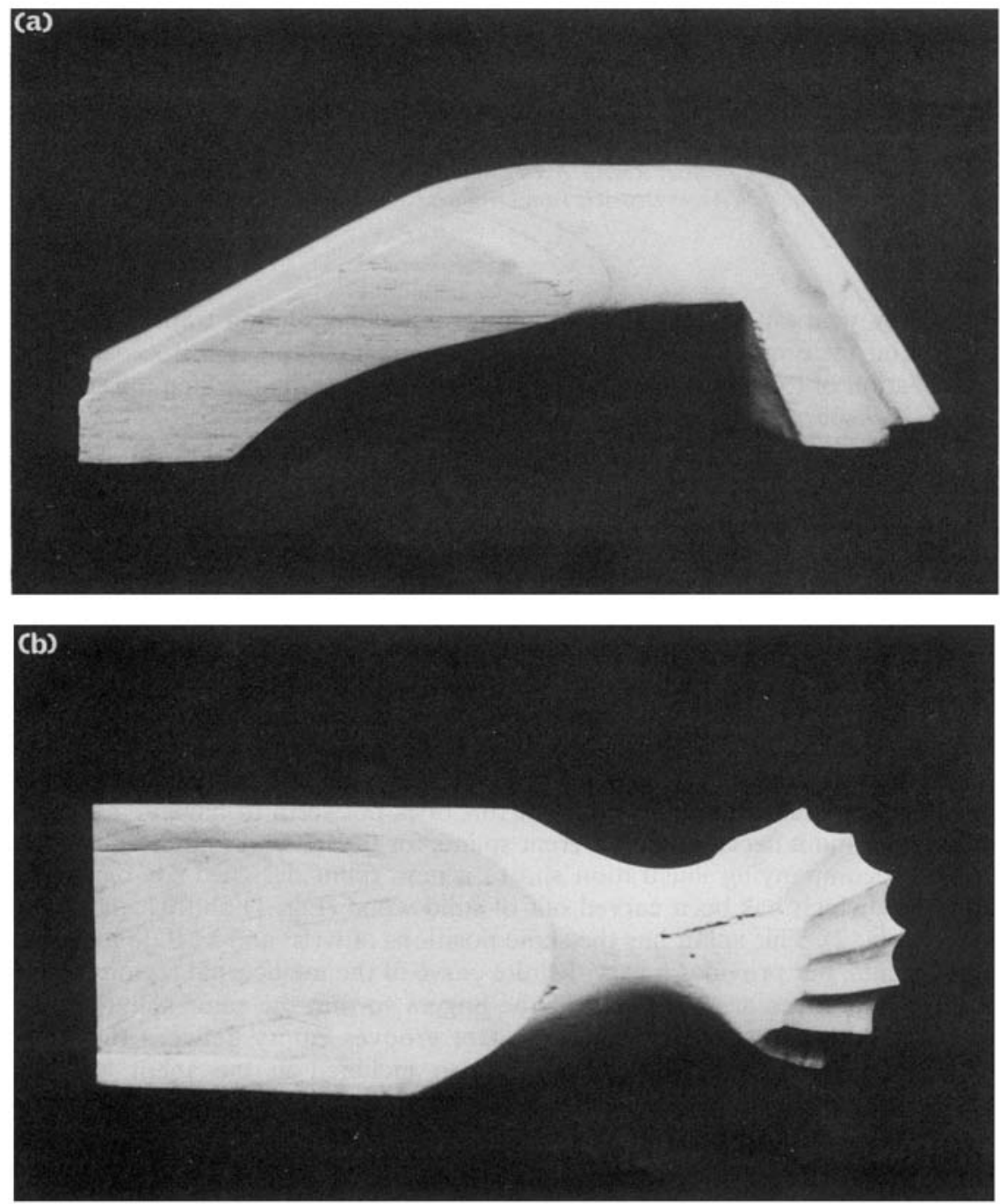

Fig. 1. (a), (b) The new positioning splint which preserves the metacarpal arch during tendon sutures. 


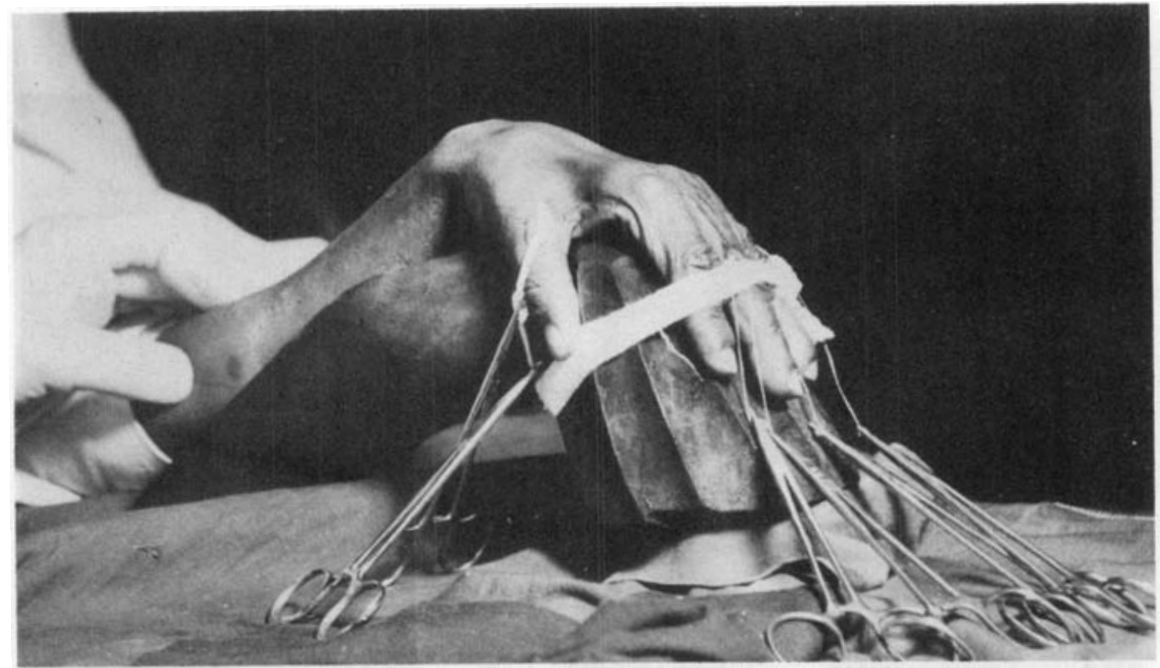

Fig. 2. The splint in use at operation.

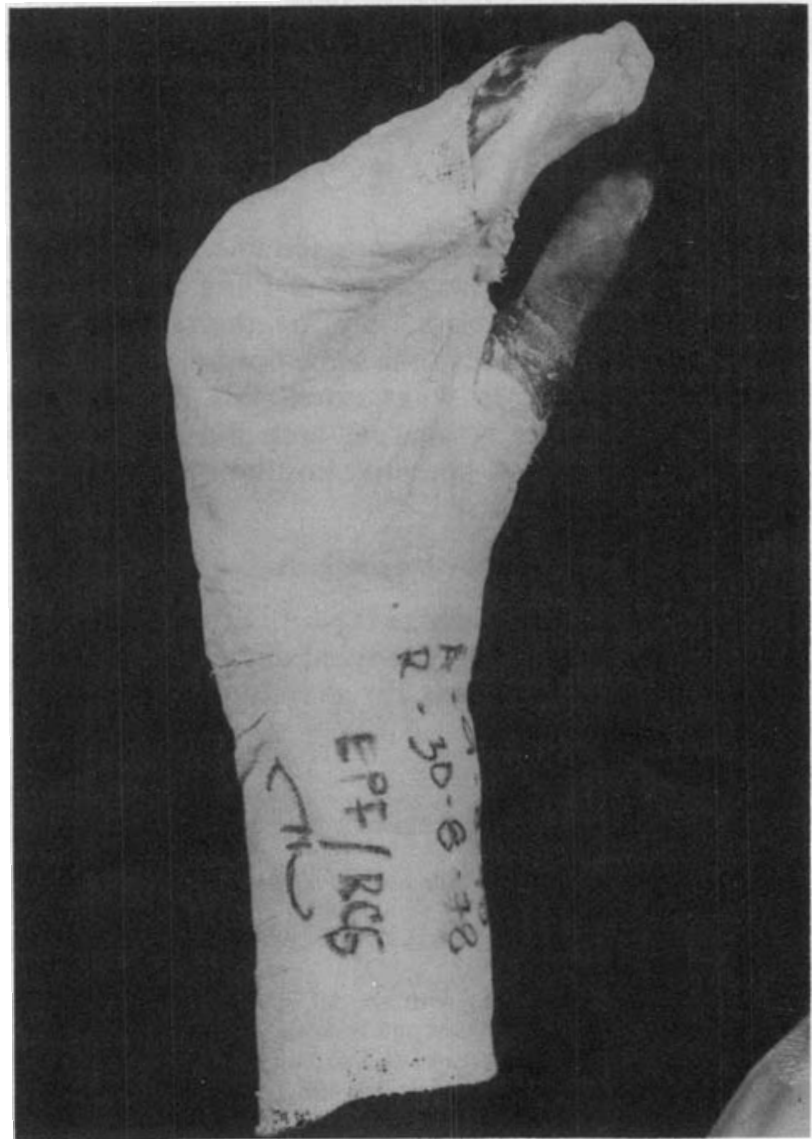

Fig. 3. Position of immobilization in plaster. 


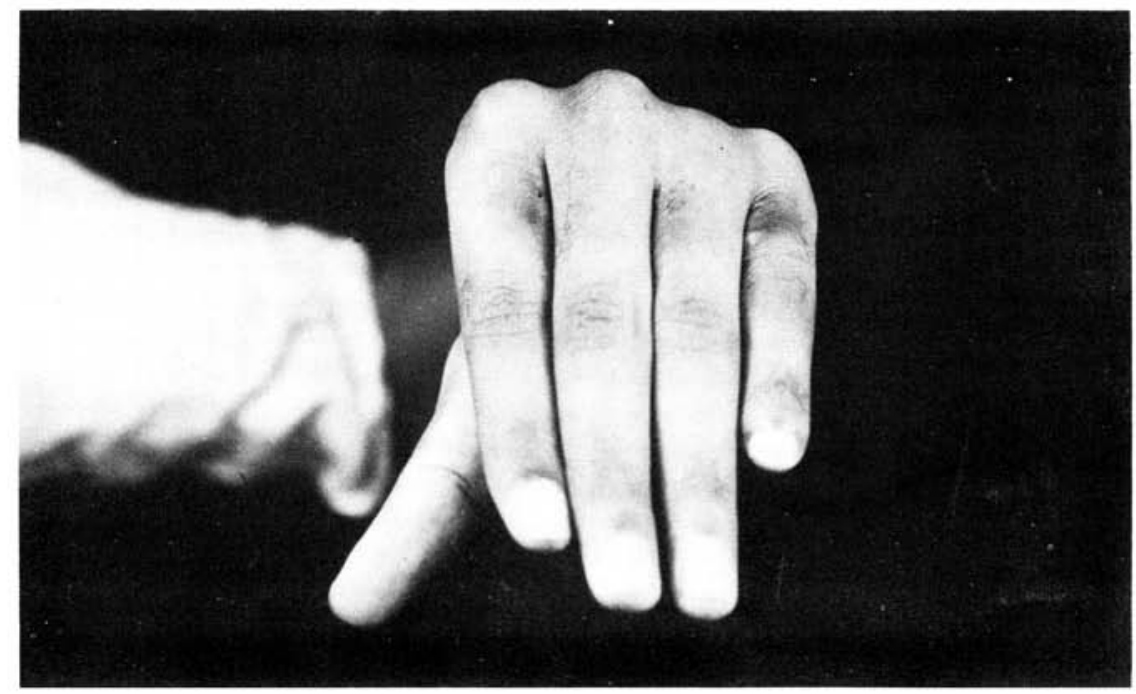

Fig. 4. Post-operative picture showing excellent arch position.

position of the metacarpal arch has been maintained throughout the healing process by applying a post-operative plaster of Paris cast with the arch very carefully preserved (Fig. 3). Thus not only are the tendons sutured in this position but also healing takes place in the same position.

It is still too early to state to what extent this has contributed to the maintenance of the transverse metacarpal arch but the early results have shown some very satisfactory post-operative positions (Fig. 4).

\section{Acknowledgements}

The author would like to acknowledge the help of Mr S. George, carpenter, in completing and finishing the prototype splint and in preparing several others since then, and of Mr K. Ramadass for the photographs and Mrs Sarala Selvaraj for typing the manuscript.

\section{References}

Antia, N. H. (1971). Review of surgery in leprosy. Int. J. Lepr. 3, 616.

Beine, A. (1974). Int. J. Lepr. 42, 303.

Boilean Grant, J. C. and Basmajian, J. V. (1965). Grant's Method of Anatomy, 7th edit., p. 192. William \& Wilkins, B altimore.

Brand, P. W. (1958). Paralytic claw hand with special reference to paralysis in leprosy and treatment by the sublimis transfer of Stiles and Bunnell. J. Bone Jt Surg. 40B, 618.

Fritschi, E. P. (1971). Reconstructive Surgery in Leprosy, p. 225. John Wright \& Sons, Bristol.

Ranney Donald, A. (1973). Plastic reconstr. Surg. 52, 406. 